\title{
Tritium Decontamination of TFTR D-T Graphite Tiles Employing Ultra Violet Light and a Nd:YAG Laser
}

\author{
C. A. Gentile, C. H. Skinner, K. M. Young, L. Ciebiera, S. W. Langish, \\ A. von Halle, C. W. Kennedy \\ Princeton Plasma Physics Laboratory, Princeton University, Princeton, New Jersey, 08543 USA \\ S. O’hira, W. M. Shu \\ Japan Atomic Energy Research Institute, \\ Tritium Engineering Laboratory, Tokai, Ibaraki 319-1195, Japan
}

\begin{abstract}
The use of an ultra violet light source (wavelength $=172 \mathrm{~nm}$ ) and a $\mathrm{Nd}$ :YAG Laser for the decontamination of TFTR D-T tiles will be investigated at PPPL. The development of this form of tritium decontamination may be useful for future D-T burning fusion devices which employ carbon plasma facing components on the first wall. Carbon tiles retain hydrogen isotopes, and the in-situ tritium decontamination of carbon can be extremely important in maintaining resident in-vessel tritium inventory to a minimum. A test chamber has been designed and fabricated at PPPL. The chamber has the ability to be maintained under vacuum, be baked to 200 ${ }^{\circ} \mathrm{C}$, and provides sample ports for gas analyses. Tiles from TFTR that have been exposed to D-T plasmas will be placed within the chamber and exposed to either UV light source or the ND:YAG Laser. The experiment will determine the effectiveness of these two techniques for the removal of tritium. In addition, exposure rates and scan times for the UV light source and/or $\mathrm{Nd}$ :YAG Laser will be determined for tritium removal optimization from D-T tiles.
\end{abstract}

\section{Introduction}

The ability to remove tritium from the surface of carbon tiles by ultra violet light and with lasers will be studied in a joint effort with members of PPPL and JAERI. Tritium accumulates with carbon in co-deposited layers on plasma facing components exposed to D-T plasmas. This phenomena is the dominant route for tritium retention in tokamaks and may severely impact the operational schedule for future long pulse machines with carbon plasma facing components [1]. At present there is an urgent need to develop efficient techniques to remove tritium from plasma facing components. In support of this project an ultra violet (UV) light source with a wavelength of $172 \mathrm{~nm}$ has been supplied by JAERI. A Nd:YAG laser (in the kilowatt range) is being procured by PPPL to also support this experiment. Tritium is released from materials at elevated temperatures thus it may be attractive to transiently heat the co-deposited layer on the tile surface by a Nd:YAG laser beam. The laser could transiently heat the surface to high temperatures (up to $2,000{ }^{\circ} \mathrm{C}$ ). Initial tests will be performed to determine the optimal laser intensity and duration. A pyrometer will be set up to monitor the surface temperature and interlocked with the laser to prevent over heating. An optical head capable of scanning the laser beam across a surface is planned to be implemented and tested. A remotely controlled scanner will be positioned to raster the laser beam. The surface temperature and heating location will be monitored including the tritium released.

During October 199936 TFTR D-T limiter tiles were collected from the TFTR vacuum vessel. These tiles are expected to contain $1-2 \mathrm{Ci}$ of tritium (as previously 
measured from tiles collected from a similar location in the TFTR vacuum vessel) codeposited on the top $\sim 1-50$ microns of the surface of the tile. These tiles will be used for the tritium decontamination study. Currently a large fraction of tritium $(\sim 7,500$ $\mathrm{Ci}$ ) held in the TFTR vacuum vessel is contained in the co-deposited layer of the limiter tiles. The retention of tritium contained in the co-deposited layer is a problem for any fusion device employing a carbon based first wall. The ability to release this tritium for recovery and possible reuse is of importance in maintaining site tritium inventories to quantities which actively support the operation of the device. Tenaciously held tritium is of no use to the operation of a fusion reactor and increases the quantity of unusable tritium at the site. In addition there are safety considerations for maintaining the first wall with as low an inventory of tenaciously held tritium as possible. Thus it is imperative that the level of tenaciously held on-site tritium inventories co-deposited on the surface of the first wall be kept to a minimum. In addition it is highly advantageous that tritium removed from the first wall be performed in a manner which maintains the formation of tritiated water to levels as low as possible. Heating first wall surfaces with a laser or exposure to UV light may provide a reasonable method for the removal of tritium.

\section{Experimental Configuration}

An experimental chamber has been fabricated which provides for safely subjecting a tritiated carbon tile to either a UV light source and laser beam (Fig. 1.). The chamber employs a sapphire window which minimizes UV light absorption thus allowing greater than $70 \%$ of UV light to enter the chamber and interact with the surface of the tile.

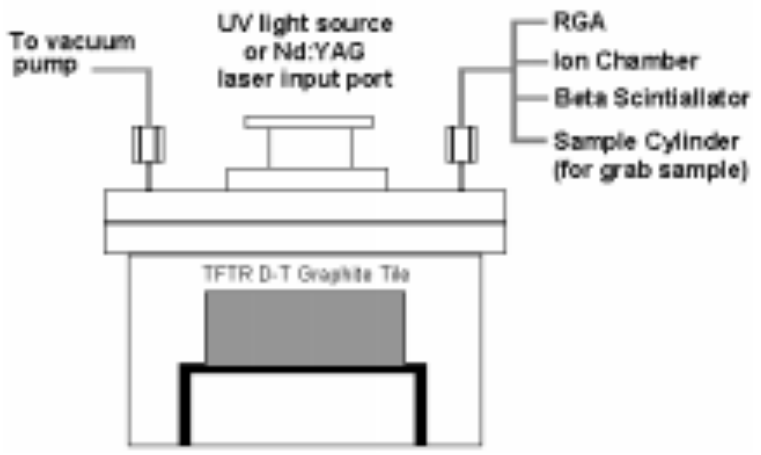

Figure 1. Vacuum Chamber Schematic

The chamber has been fabricated to provide gas ports for analysis. In addition the chamber has a dynamic pressure range of $1.0 \times 10^{-6}$ torr to 2000 torr and can be baked to $200{ }^{\circ} \mathrm{C}$. Pressure and temperature will be set to optimize tritium removal rates.

Carbon tiles (Fig. 2) that have been exposed to TFTR D-T plasmas will be placed in the chamber and can be positioned in virtually any geometry required to optimize the interaction with both UV and laser light.

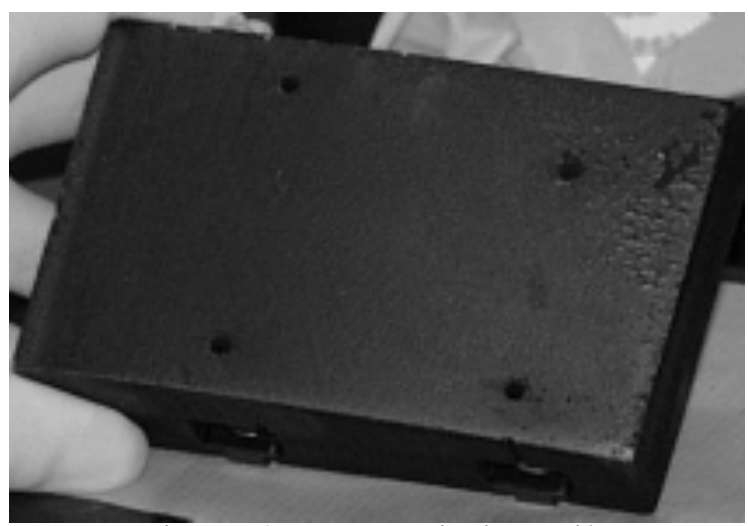

Figure 2. TFTR Limiter Tile

When exposed to one of these energy sources, tritium liberated from the surface of the tile is measured by a real time tritium monitor, thus providing feedback to the experimentalist on the effectiveness of the laser beam intensity, and duration.

A tile mapping system has been developed which subdivides the surface of the tile into 24 distinct locations, thus providing tile coordinates for those areas exposed to the externally generated energy source. 


\section{Experimental Plan}

Prior to placing the tile into the test chamber for UV light and laser exposure the surface of the tile will be analyzed employing non-destructive methods. A matrix of 24 thermo luminescent dosimeters (TLD's) will be first positioned on the surface of the tile to measure tritium activity. After TLD measurements the surface will then be measured with an open wall tritium monitor. After tritium measurements have been made employing these non-destructive methods the tile will be placed in the chamber and subjected to either UV light or laser energy. During exposure to UV light or laser discreet mapped sections on the surface of the tile are exposed to the energy source. During exposure the quantity of tritium that is liberated from the tile surface will be measured with a tritium calibrated ion chamber. During the exposure time the pressure in the chamber can be lowered to a high vacuum range (less than $1 \times 10^{-6}$ torr) or increased to greater than 2 atmospheres. The dynamic temperature range of the chamber is $20{ }^{\circ} \mathrm{C}$ to $200{ }^{\circ} \mathrm{C}$.

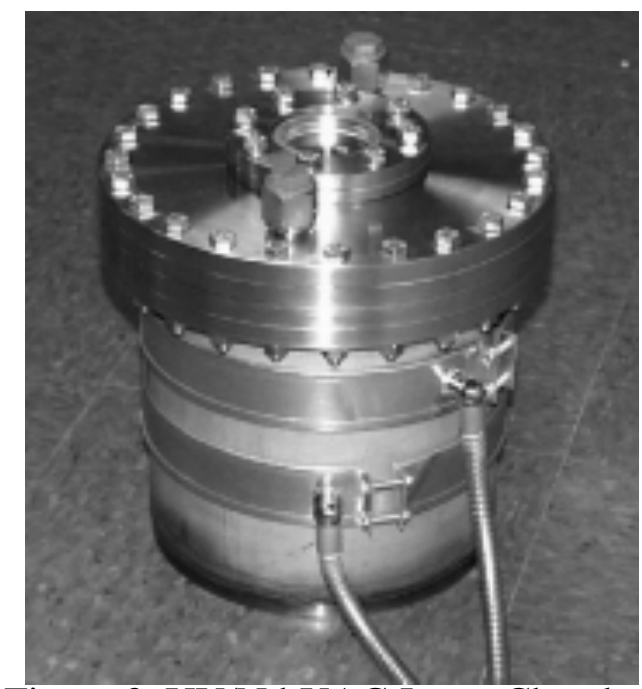

Figure 3. UV/Nd:YAG Laser Chamber

Temperature and chamber pressure can be set as determined by tritium measurements that are provided real time to the experimentalist indicating the rate of tritium release from the surface of the tile. After a tile has been subjected to UV light and/or laser the tile will be removed from the chamber and TLD and ion chamber measurements re-taken. After TLD and ion chamber measurements the tile will be baked out to $500{ }^{\circ} \mathrm{C}$ in a special bakeout oven to collect and tritium remaining in the tile.

\section{Future Plans}

It is expected that one third of the tiles collected during the October 1999 TFTR vacuum vessel entry [4] will be subjected to UV light and laser irradiation to determine the effectiveness of these energy sources in releasing tritium from the codeposited layer.

\section{References \\ [1] G. Federici et al., "In-vessel tritium retention and removal in ITER", Journal Nuclear Material, pgs. 266-269 (1999).}

[2] C. H. Skinner, H. Kugel, D. Mueller, B. L. Doyle, W. R. Wampler, "Tritium removal by $\mathrm{CO}_{2}$ laser heating". Proceedings of SOFE 97, $17^{\text {th }}$ IEEE INPSS Symposium on Fusion Engineering, Oct. 6-9, 1997.

[3] Y. Kameo, K. Aoki, T. Gorai, T. Hirabayashi, "Development of laser decontamination technique for metal wastes". Water Chemistry 1998 Proceedings Pgs. 571-574, Kashiwazaki, Japan 1998.

[4] C. H. Skinner, C. A. Gentile, K. M. Young, "Observations of flaking of codeposited layers in TFTR", Proceedings of the Symposium of Fusion Energy, presented at $18^{\text {th }}$ IEEE/NPSS Symposium on Fusion Engineering, Albuquerque, New Mexico, Oct. 25 29, 1999. 